Participants in the trial: G. S. Kellaway, Auckland (Convenor); T. Gebbie, Wellington; A. C. Hayton, New Plymouth; P. E. Holst, Dunedin; A. R. Kirk, Nelson; M. Kirk, Palmerston North; J. A. McLeod, Christchurch; T. V. O'Donnell, Dunedin; J. J. O'Hagan, Invercargill; and R. G. P. Rothwell, Hamilton.

\section{References}

Altounyan, R. E. C. (1968). Acta Allergica, 22, 487

Altounyan, R. E. C., and Howell, J. B. L. (1969). Respiration, 26, Suppl. No 131 .

Bernstein, L., et al. (1971). Journal of Allergy, 47, 95.
Cayley, F. E. (1970). Disodium Cromoglycate in Allergic Airways Disease, p. 44. London, Butterworths.

Cotes, J. E. (1966). I.L.O. Occupational Safety and Health Series, No. 6. Gianoutsos, P., and O'Donnell, T. V. (1969). New Zealand Medical fournal, 70,311.

Grant, I. W. B. (1968). Lancet, 2, 282.

Grant, I. W. B., Channell, S., and Drever, J. C. (1967). Lancet, 2, 673.

Howell, J. B. L., and Altounyan, R. E. C. (1967). Lancet, 2, 539

Kennedy, M. C. S. (1967). Lancet, $2,838$.

Marshall, J. S., and Birtwistle, I. H. (1970). Disodium Cromoglycate in Allergic Airways Disease, p. 173. London, Butterworths.

Medical Research Council (1965). Lancet, 1, 776.

Pepys, J., Chan, M., Hargreave, F. E., and McCarthy, D. S. (1968). Lancet, 2, 134

Read, J., and Rebuck, A. S. (1969). Medical fournal of Australia, 1, 566. Tocker, D., and O'Donnell, T. V. (1972). New Zealand Medical fournal. In

Woolcock, A. J., and Read, J. (1966). American fournal of Medicine, 41, 259

\title{
Effects of Four Commonly-used Tranquillizers on Low- speed Driving Performance Tests
}

\author{
T. A. BETTS, A. B. CLAYTON, G. M. MACKAY
}

British Medical fournal, 1972, 4, 580-584

\begin{abstract}
Summary
A double-blind controlled comparison of four commonlyused tranquillizing drugs (haloperidol, amylobarbitone sodium, chlordiazepoxide, and trifluoperazine) against placebo was made in their effects on the performance of volunteers during three low speed vehicle-handling tests. The drugs (with the exception of haloperidol) significantly altered driving behaviour though they did not seem to interact significantly with alcohol. There is, therefore, a strong possibility that such drugs will similarly alter driving performance in patients taking them for therapeutic purposes. Since, as these experiments also show, those affected may be subjectively unaware of it, and routine clinical screening is not sensitive enough to detect them, physicians should warn patients of the probability that their driving performance will be affected by such drugs, particularly during the first few days that they are taken.
\end{abstract}

\section{Introduction}

Road accidents are a leading cause of death and morbidity, particularly in young people. Alcohol is directly involved in many of these accidents, and there is growing concern that the large amount of psychotropic medication currently prescribed in the Western hemisphere may also be involved. Several authors have recently reviewed the large amount of literature that reflects the growing interest in this problem (Havard, 1970; Kibrick and Smart, 1970; Waller, 1971; Milner, 1972), though evaluation of the effect of psychotropic drugs on driving performance is much more difficult and has many more methodological problems than studying the effect of alcohol on driving.

This is largely due to the unique pharmacological properties of alcohol. Unlike alcohol, however, the absorption of psycho-

\section{University Department of Psychiatry, Queen Elizabeth Hospital, Birmingham}

T. A. BETTS, M.B., D.P.M., Senior Lecturer in Psychiatry

Department of Transportation and Environmental Planning, The University, Birmingham

A. B. CLAYTON, B.SC, PH.D., Senior Research Associate

G. M. MACKAY, PH.D., M.I.C.E., Senior Research Fellow tropic drugs may be erratic, their metabolism is often complex (the effects of a drug may be difficult to distinguish from those of its related metabolites), and excretion is slow-indeed a patient may still be excreting the drug in the urine several weeks after he has taken his last dose. Blood levels of the drug may have little relation to drug effect, and may not correlate with urine levels of the drug. Dose response relations are more complex than those of alcohol, and the amount of idiosyncratic response or individual variation in response is probably much greater than with alcohol. There is a strong placebo element in drug response.

Psychotropic medication is taken by patients suffering from emotional symptoms or illnesses (which have their own complex effects on performance), and the medication has to be taken regularly. It is unrealistic, therefore, to study the effects of a single dose of a drug on driving performance (as can be done legitimately with alcohol). The use of normal subjects in such experiments also has a slightly limited value.

The direct causal involvement of drugs in road accidents has been examined by determining whether psychotropic drugs were present in the body tissues, blood, or urine of drivers killed or injured in road accidents or involved in traffic violations (reviewed by Havard, 1970). However, no properly controlled study of psychotropic drugs in accident situations has been carried out to compare with the classic study of Borkenstein et al. (1964) on the involvement of alcohol in road accidents, and in the present state of the art we doubt if it could be.

Most studies of the interaction between psychotropic drugs and driving behaviour have been in the laboratory, mostly involving driving simulators (devices of varying complexity in which a number of skills resembling driving can be tested simultaneously). Unfortunately, a simulator needs to be extremely sophisticated to match the demands of an actual driving situation. In addition the attitude and "set" of a subject "driving" in a simulator are likely to be different from his attitude to real driving. Different models (each with their own method of measurement) have been used in the various studies undertaken, and replication experiments have not been done.

In many simulator studies little allowance has been made for practice effects and little pretest training has usually been given. Sometimes sufficient time has not been allowed for absorption and metabolism of the drug before testing.

Most experimenters have used single doses or once repeated doses of the drug under test though some chronic experiments have been done with meprobamate (Kelly et al., 1958a, 1958b).

The results of many simulator studies are now partly irrele- 
vant as the drugs included in these experiments are now no longer widely prescribed. Yet many of the generalized statements made about drugs and driving interaction are based on results of simulator studies using such obsolescent drugs. Milner (1972) has reviewed the latest simulator work, which suggests that there is an initial drug effect on driving skills which is worsened by alcohol, but always the problem of extrapolating the results to the real driving situation remains.

Vehicle handling tests have been used widely in alcohol studies, and therefore a prima facie case exists for their use in psychotropic drug studies. However, only two such studies using vehicle handling tests have been carried out. These were by Kielholz et al. $(1967,1969)$ using members of the Basle police force who underwent five driving tests using a standard police car. Subjects were given the active drug or an identical placebo on a double-blind basis, and in addition half the subjects took a dose of white wine to bring their blood alcohol levels up to $80-100 \mathrm{mg} / 100 \mathrm{ml}$. A major criticism of the experiment is that subjects had only a short time to practice before the experiment started (15 minutes or less), and they drove over the test course only two hours after taking the single dose of the drug used. Results showed that $200 \mathrm{mg}$ of phenobarbitone significantly impaired driving ability whereas $10 \mathrm{mg}$ and $20 \mathrm{mg}$ of chlordiazepoxide and $400 \mathrm{mg}$ and $800 \mathrm{mg}$ of meprobamate did not. The larger dose of chlordiazepoxide and meprobamate and $200 \mathrm{mg}$ of phenobarbitone all significantly potentiated the deleterious effects of alcohol.

We present here the preliminary results of an experiment to determine whether small repeated doses of four commonly-used tranquillizing drugs affected performance on low speed vehiclehandling tests. For the reasons discussed above we feel that such tests are, at present, the best way of evaluating the interaction between psychotropic drugs and driving.

\section{Method}

\section{VEHICLE HANDLING TESTS}

Three vehicle handling tests ( 1 , a weaving test; 2 , a parking test and 3, a gap estimation test) were set up on a private car park (see Fig.). All subjects used the same vehicle, a Ford Escort saloon (length $13 \mathrm{ft} 0.6$ in $(4 \mathrm{~m})$ ). The dimensions of the test course were proportionate to the length of the car so that in test 1 the distance between the successive bollards was $1 \frac{1}{2}$ times

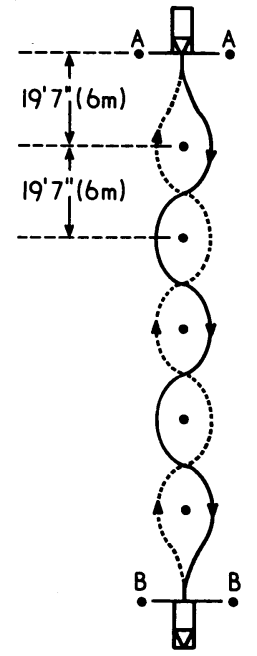

TEST 1
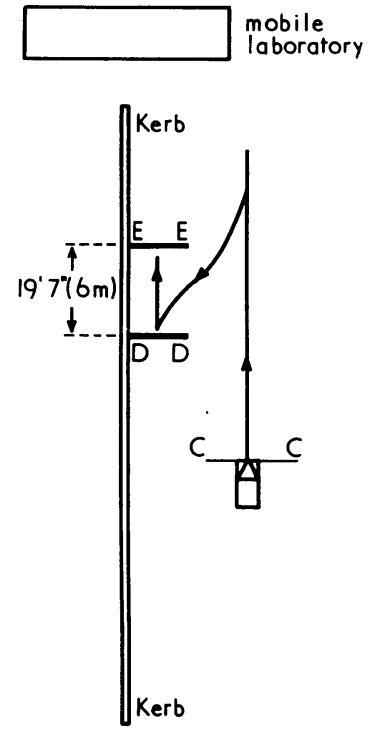

IEST 2

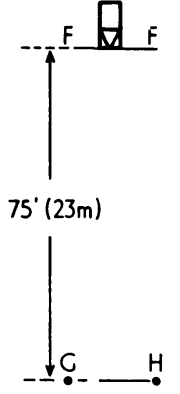

TEST 3 the length of the car, as was the distance between the "parked vehicles" used in test 2 . At least two marshals supervised each test. The instructions given to the subjects were as follows.

Test 1.-Start with front wheels on line AA. Drive forward on signal from marshal. Zigzag between the bollards shown, passing to the left of the first bollard. Drive over the line BB. The rear wheels must cross it. Then reverse back, passing on the opposite sides of the bollards, and finally drive over line AA. The front wheels must cross it. Shunting back and forth is permitted. The test should be completed as quickly as possible, but touching a bollard will incur a penalty.

Test 2.-Start with front wheels on line CC. Proceed ahead as far as necessary. Reverse into the gap between the white boards DD and EE representing "parked vehicles" and park the car so that the nearside wheels are as close as possible to, and equidistant from, the kerb. This test is not timed. Only three movements are permitted from CC, forward, reverse, and forward. Touching either "parked vehicle" or touching the kerb will incur a penalty.

Test 3.-Start with front wheels on line FF. One bollard, G or $\mathrm{H}$, will be fixed, the other bollard will be moved by a marshal on instructions from the subject along the line GH until the subject is satisfied that he can drive through the gap with minimum clearance. The gap will then be measured. The car is then driven forward and stopped with its widest part along the line GH. Neither bollard should be touched. No reversing is permitted. This test is not timed. Drivers were instructed to remain seated throughout the test and to keep the car doors closed, but were allowed to look out of the off-side window.

\section{Subjects}

The subject sample consisted of 113 volunteers, mainly students, the first 13 of whom were used in a pilot study to test the vehicle handling techniques. Before being accepted for the experiment they were interviewed by the medical member of the team (T.A.B.) and were excluded from the experiment if, in his opinion, they were suffering from some medical or psychiatric condition which would have invalidated the tests or put the subject at risk from the drugs being studied. All subjects had to hold full driving licences and had to be between 18 and 30 years of age. Informed and valid consent was obtained. They were free to drop out of the experiment at any time, and throughout all weekends of the experiment the medical member of the team was on call for consultation about unpleasant symptoms or side effects.

Various other tests were given to the subjects during the course of the experiment. They were visually screened (Keystone Ophthalmic Telebinocular), they completed the Eysenck Personality Inventory (Eysenck and Eysenck, 1964), and they answered a biographical and driving history questionnaire giving details of age, occupation, and driving experience, total mileage driven, number of accidents and driving convictions, and car ownership.

In addition, at various times during the experiment they were examined on the following.

Objective Assessment Scale.-This was an objective emotional, behavioural, and neurological assessment of the subject carried out by T.A.B., adapted from that used by Reisby and Thielgaard (1969). Subjects were rated on the objective presentation of mood (spirits, affective contact, facial expression), anxiety (tension, anxiety, irritability), and general liveliness (speech tempo, motor tempo) on a five-point scale from "much more than normal" to "much less than normal." In these assessments the subject acted as his own control and was judged against his own standards of "normality" that had been assessed during the initial medical interview and during the subject's initial practice session on the test course. The subjects were then rated on a three-point scale in terms of sleepiness, concentration, tremor of hands, Romberg's test, nystagmus, finger-nose test, and speech. 
Subjective Feeling Questionnaire.-At specific times during the experiment subjects were given a short questionnaire which asked them to rate themselves on a five-point scale from "much less than usual" to "much more than usual" against the following parameters, again adapted from Reisby and Thielgaard (1969): tired, sleepy, detached, indifferent, tense, restless, irritable, despondent, apprehensive, cheerful, self confident, able to concentrate, found it easy to control your movements, found your hands shaking. At the very end of the experiment subjects indicated when they thought they had taken the active drug. The observer (T.A.B.) made a similar independent estimate.

\section{Drugs}

Four tranquillizing drugs were used in this experiment to represent the four main classes of tranquillizers.

Chlordiazepoxide (Librium) represented the benzodiazepine group of drugs. It was accused on the basis of anecdotal evidence of causing lapses of attention with consequent traffic accidents in an uncontrolled study by Murray (1960). Subjects took five 10-mg doses over 36 hours.

Amylobarbitone sodium (Sodium Amytal) represented the barbiturates. Subjects took five $30-\mathrm{mg}$ doses over 36 hours. To have made doses strictly comparable with chlordiazepoxide subjects should have taken 60-mg doses (Lader and Wing, 1966) but a pilot study showed that normal people taking this amount were too drowsy to be able to work properly, and the smaller dose had to be used.

Trifluoperazine (Stelazine) represented the phenothiazine drugs. Subjects took five 2-mg doses over 36 hours (there is no exact "comparable" dose, but this is the normal dose level when this drug is used as a minor tranquillizer).

Haloperidol (Serenace) represented the butyrophenone group of drugs. Subjects took five $0.5-\mathrm{mg}$ doses over 36 hours, which is the normal anxiolytic dose.

\section{ADMINISTRATION}

The doses were therefore about equal. All the drugs in the study, including the placebos, were made up in the same size white tablets. The weights of all the subjects were recorded.

Five doses of these drugs were taken in the 36 hours before one of two test periods held on consecutive Sundays: over the 36 hours before the other test period subjects took five doses of the placebo under double-blind conditions. The order of administration of drug or placebo was randomized (to obviate practice effects) so that 10 subjects (five men, five women) took each of the active drugs first and a similar number took them second. In addition, 20 subjects (10 men, 10 women) took a placebo before both test periods (again under double-blind conditions) to act as a control group to measure any practice effects. The subjects were randomly assigned to one of these five groups.

\section{Test Procedure}

Subjects were used in batches of six every fortnight. They first arrived at the test site on a Wednesday afternoon where a mobile laboratory was installed. They were given the following tests: (1) visual screening test, (2) Eysenck Personality Inventory, (3) biographical and driving history questionnaire, (4) subjective feeling questionnaire, and (5) objective assessment. Having completed these tests they were allowed a few minutes' practice drive and were then given the instruction sheet. The first practice session consisted in: test 1,6 runs; test 2,4 runs; test 3,3 runs; test 1,6 runs.

At the end of this first practice session they were given two bottles containing the appropriate drugs, and were given explicit instructions about when and how to take them. They were warned not to drink, drive, or undertake other hazardous activities while taking both drugs. They arrived back at the test centre on the following Sunday morning, after eating a fat-free breakfast, and completed the subjective feeling questionnaire and the objective assessment. They then completed the driving test: test 1, 3 runs; test 2,3 runs; test 3,5 runs.

They were then given a measured dose of alcohol (at the rate of $0.5 \mathrm{gm}$ of alcohol per $\mathrm{kg}$ of body weight) in a flavoured sugar base, which was sufficient to bring their blood alcohol levels up to about $50 \mathrm{mg} / 100 \mathrm{ml}$. They waited for an hour and then completed the subjective feeling questionnaire and the objective assessment scale again. In addition they had an alcohol screening test (Borkenstein Breathalyser) which provided an estimate of individual blood alcohol levels, and then finally took the driving test again. On the following Wednesday they attended a similar practice session to the first Wednesday, and the following Sunday they completed the same procedure as on the first Sunday.

\section{Results}

Altogether, 100 subjects ( 50 men and 50 women) were included in the analysis of data. They were divided into five groups, chlordiazepoxide against placebo, haloperidol against placebo, amylobarbitone sodium against placebo, trifluoperazine against placebo, and the double placebo group. There were 10 men and 10 women in each group.

The men had had significantly more driving experience $(2 \%$ level), had driven significantly more miles (1\% level), and had significantly more driving convictions ( $2 \%$ level) than the women drivers. On the other hand the women scored significantly higher on the $\mathrm{N}$ scale of the Eysenck Personality Inventory $(2 \%$ level). The mean blood alcohol levels of the subjects on the two test days were very similar, $52.85 \mathrm{mg} / 100 \mathrm{ml}$ on the first and $52.40 \mathrm{mg} / 100 \mathrm{ml}$ on the second. There were no significant differences between the five groups of subjects on any of the above variables.

\section{VEHICLE HANDLING TESTS}

A summary of significant results obtained in the drug groups on the vehicle handling tests is presented in Table I. Results refer to effects under drug conditions, and all significance levels are at $5 \%$ or better.

TABLE I-Summary of Significant Results in Vehicle Handling Tests by Drug Group

\begin{tabular}{|c|c|c|}
\hline Drug Group & Men & Women \\
\hline $\begin{array}{lll}\text { Trifluoperazine } & & \ldots \\
\text { Haloperidol } & & \\
& . & \end{array}$ & 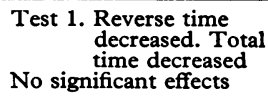 & $\begin{array}{l}\text { Test 1. Forward time } \\
\text { increased. Total } \\
\text { time increased }\end{array}$ \\
\hline Chlordiaxepoxide & $\begin{array}{l}\text { Test 1. Reverse time } \\
\text { increased. Total } \\
\text { time increased }\end{array}$ & $\begin{array}{l}\text { Test 3. Mecreased } \\
\text { decreased }\end{array}$ \\
\hline Amylobarbitone Sodium & $\begin{array}{l}\text { Test 3. Mean failure } \\
\text { gap increased }\end{array}$ & $\begin{array}{l}\text { Test 2. Distance from } \\
\text { Test 3. Merb decreased } \\
\text { increased }\end{array}$ \\
\hline
\end{tabular}

Results refer to effects under drug conditions. All significance levels at $5 \%$ or better.

\section{TEST 1}

In this test measurements were made of the time taken to complete the test successfully (forward, reverse, and total time) and the number of bollards hit. The control group results showed that there was no learning effect between the two test sessions in terms of time taken (men were significantly faster than women on this test) but that both men and women were more accurate -that is, hit significantly fewer bollards-in the second test period. 
TABLE II-Summary of Significant Results of Objective Assessment Scale by Drug Group (Men and Women Combined)

\begin{tabular}{|c|c|c|c|}
\hline Trifluoperazine & Haloperidol & Chlordiazepoxide & Amylobarbitone Sodium \\
\hline \multicolumn{4}{|c|}{ Without Alcohol } \\
\hline Reduced tremor & $\begin{array}{l}\text { Decreased spirits. Decreased } \\
\text { ness of facial expression }\end{array}$ & liveli- | No significant objective effects & $\begin{array}{l}\text { Increased spirits. Increased affective } \\
\text { contact. Increased liveliness of facia } \\
\text { expression }\end{array}$ \\
\hline \multicolumn{4}{|c|}{ With Alcohol } \\
\hline $\begin{array}{l}\text { Increased affective contact. Increased speech } \\
\text { tempo. Increased liveliness of facial ex- } \\
\text { pression. Increased tremor }\end{array}$ & Reduced nystagmus & Increased Romberg's sway & No significant objective effects \\
\hline
\end{tabular}

Significance levels at $5 \%$ or better.

When the drug groups were compared with placebo (using the split plot analysis of variance) significant differences emerged (see Table I) in terms of time taken to complete the tests. There was no interaction with alcohol, and the drugs did not affect accuracy on this test.

\section{TEST 2}

Two measures were made in this test-final distance from the kerb, and the number of hits on "parked vehicles" or on the kerb. Control group results showed that the only learning effect occurring between the two sessions on this test was in women, who were more accurate- that is, hit less-in the second session. Men and women in this group were equally accurate.

Comparison between drug and placebo groups (using split plot analysis of variance) showed only one significant difference (see Table I). One such result could have occurred by chance, and suggests that either the skills needed to do this test were not affected by the drugs, or that it was not sensitive enough. There was no interaction with alcohol.

\section{TEST 3}

The measures of performance used on this test were: number of successes and failures - that is, the number of occasions on which the subject succeeded or failed to drive through the chosen gap without regard to its size; the mean success gap-that is, the mean of all the chosen gaps through which the subject drove successfully without hitting the bollards; and the mean failure gap-that is, the mean of all the chosen gaps through which the subject drove and hit one or both of the bollards.

The number of successes and failures in each group were compared using the chi square test. There were no significant differences, and no interaction with alcohol.

For the "mean success" and "mean failure" gaps the results were analysed using the technique of analysis of variance with subgroups of differing sizes (Walker and Lev, 1953). In the control group men became significantly more careless in week two; women were significantly more careful than men, and alcohol actually improved their performance. Significant results obtained by comparing drug versus placebo conditions are summarized in Table I. There was one significant drug/ alcohol interaction when with alcohol plus chlordiazepoxide in women the "mean failure gap" was decreased. This one result could have been due to chance.

A total of $88 \mathrm{drug} /$ test/subject interactions were evaluated in the vehicle handling tests. It could have been expected that four or five of these interactions would have been significant by chance expectation alone. The number of significant results (11) far exceeds this, and there is therefore a significant overall drug effect $(1 \%$ level), though for reasons discussed later the results are not consistent either between drug groups or between the sexes. There is only one significant result for haloperidol, which could have occurred by chance.

\section{OBJECTIVE ASSESSMENT RESULTS}

Comparison between the various drug/placebo and drug/ alcohol conditions were made by assigning scores of 1 to 5 to the various categories on the objective assessment scale (or 1 to 3 on the three-point scale) and then using these scores in the Wilcoxon matched-pairs signed-ranks test (Siegel, 1956).

There were no differences on any of the assessment scores between week 1 and week 2 in the control group. When, however, the with-alcohol scores in this group are compared for week 1 and week 2 significant differences emerge, and suggest that subjects had developed tolerance to the emotional effects of alcohol in the second week.

The significant objective assessment results for the four drug groups, and for the four drug groups plus alcohol (men and women combined) are presented in Table II. All significance levels are at least at the $5 \%$ level. The results show that haloperidol had a significant depressant effect and amylobarbitone sodium a significant euphoriant effect in these normal subjects whereas the other two drugs produced no significant objective change (one significant result could have occurred by chance). Trifluoperazine interacted to a significant extent with alcohol to produce euphoria, but there was no other significant drug/ alcohol interaction (again a single significant result could have occurred by chance). There were no significant differences between men and women considered separately.

The results of the observer's assessment as to which weekend the subjects had taken the active drug are shown in Table III. Subjects taking amylobarbitone sodium or chlordiazepoxide

TABLE III-Results of Objective Estimate of When Subject Took Active Drug by Groups (Men and Women Combined)

\begin{tabular}{|c|c|c|c|c|c|c|}
\hline \multicolumn{4}{|c|}{ Group } & No. Right & No. Wrong & Total \\
\hline $\begin{array}{ll}\text { Control group* } & \ldots \\
\text { Haloperidol } & \ldots \\
\text { Trifluoperazine } & \ldots \\
\text { Chlordiazepoxide } & \vdots \\
\text { Amylobarbitone sodium }\end{array}$ & $\begin{array}{l}\because \\
\because \\
\because \\
\cdots\end{array}$ & $\begin{array}{l}\ldots \\
\cdots \\
\cdots\end{array}$ & $\begin{array}{l}\ldots \\
\cdots \\
\cdots\end{array}$ & $\begin{array}{c}5 \\
10 \\
7 \\
15 \dagger \\
16 \ddagger\end{array}$ & $\begin{array}{l}15 \dagger \\
10 \\
13 \\
5 \\
4\end{array}$ & $\begin{array}{l}20 \\
20 \\
20 \\
20 \\
20\end{array}$ \\
\hline
\end{tabular}

"To be "right" in the control group the observer had to be unable to decide which weekend the subject had taken an active drug. Unlike the subjects he was aware of the existence of a control group.

t Significant (two-tailed) at $5 \%$ level. Binomial test, Walker and Lev (1953).

$\$$ Significant (two-tailed) at $1 \%$ level.

could be identified better than would be expected by chance. It is interesting, however, that subjects in the control group could not be identified with even chance expectancy though the observer knew that a control group existed.

\section{SUBJECTIVE ASSESSMENT}

Comparison of scores was made in the same manner as with objective testing using the Wilcoxon matched-pairs signed-ranks test. Significant findings ( $5 \%$ level or better) are in Table IV. In the control group there were no significant subjective differences between week 1 and week 2 though the subjects felt subjectively significantly more affected by alcohol in the first week 
TABLE IV-Summary of Significant Results of Subjective Assessment Scale by Drug Group (Men and Women Combined)

\begin{tabular}{|c|c|c|c|}
\hline Trifluoperazine & Haloperidol & Chlordiazepoxide & Amylobarbitone Sodium \\
\hline \multicolumn{4}{|c|}{ Without Alcohol } \\
\hline No significant subjective effect & 1 No significant subjective effect & I No significant subjective effect & I No significant subjective effect \\
\hline \multicolumn{4}{|c|}{ With Alcohol } \\
\hline Less irritable & $\begin{array}{l}\text { More despondent } \\
\text { More tense }\end{array}$ & No significant subjective effects & Less tired. Less sleepy \\
\hline
\end{tabular}

(which supports the objective assessment). None of the drugs produced significant subjective changes. Haloperidol with alcohol made subjects feel worse, whereas amylobarbitone sodium with alcohol had a subjective stimulant effect.

In no group could subjects identify the weekend in which they took the active drug with better than chance expectancy.

\section{Discussion}

In designing an experiment to measure psychotropic drug and driving interaction it was found necessary to compromise between theoretical considerations of methodology and practical possibilities. It was felt that low speed vehicle-handling tests were the best possible approximation to the real driving situation, and the best way of measuring this interaction at the present time.

It was also felt to be essential that subjects should have become proficient on the tests before drug ingestion, that a chronic experiment was necessary, and that strict double-blind conditions should apply.

It would have been desirable to administer alcohol under similar double-blind conditions, using a placebo, but as other authors (Reisby and Theilgaard, 1969) have shown there is no acceptable alcohol placebo. If ill patients had been used in this study the experimental design would have to have been very complex (and would have posed ethical difficulty). As tranquillizing drugs are so widely used in our society many "normal" people take them, so that the use of normal subjects was fairly appropriate.

The subjects were within a narrow age band. However, as both men and women who covered a wide range of driving experience were used our group was more representative of the general driving population than in most experiments. To have obtained a completely representative sample would have made the experiment far too long.

The effects of the drugs on these subjects vary between those that can be considered a worsening of the subjects' performance -for example, forward time increased-and those that can be considered an improvement-for instance, reverse time decreased. However, any change "good" or "bad" induced in a driver's performance is dangerous since it means that his behaviour has been changed in unpredictable ways. We do not, for instance, encourage drivers to drink because small doses of alcohol sometimes improve performance.

The fact that subjects could not identify which weekend they had taken the drug has the practical meaning that a person taking such a drug cannot recognize whether or not the drug is affecting him. Though objective assessment could identify when a subject had taken a drug better than subjective assessment it relied heavily on previous knowledge of the subject to assess drug effect.

One surprising finding does emerge from these studies. There was no evidence of any significant interaction between these drugs and alcohol. This is probably due to the comparatively low social levels of alcohol administered, and to the chronic nature of the drug ingestion which has eliminated some of the effects that other workers, using acute administration of the drug and higher doses of alcohol, have found. The present experiment is, however, nearer to the real life situation.

\section{Conclusions}

The results show that these psychotropic drugs (with the probable exception of haloperidol) affected performance on low speed vehicle-handling tests, and there is, therefore, a strong possibility that they will affect performance in a real driving situation. There was, however, little interaction between the drugs and alcohol under the conditions of this study. Because of the complex nature of the drug/driving problem it is extremely difficult to generalize the results beyond the specific conditions of this study. The potential danger of driving while under the influence of psychotropic medication is accentuated by the lack of correlation between change in performance on a driving test and subjective and objective assessments of drug effects. We feel it is, therefore, important that physicians should inform their patients of the potential dangers involved and warn them against driving at least during the first few days of a course of psychotropic medication with these particular drugs, particularly as changes may be taking place in driving behaviour without patients being aware of them. The present experiments, however, can say nothing about the effects of such drugs taken for a onger period of time than a few days.

This project was helped at various stages by many people. Professors J. Kolbuszewski and W. H. Trethowan provided the necessary departmental facilities, and Dr. C. P. Fonseka helped with much of the initial planning. Mr. F. R. Fletcher looked after the test vehicle and the mobile laboratory. and kept both in running order. Mr. A. E. Marston, chief pharmacist, Queen Elizabeth Hospital, kindly provided the alcohol mixture. Miss J. Burgess Smith, research secretary, department of psychiatry, very efficiently ran the complex administration of the project. Mr. $\mathbf{H}$. R. M. Hayes and Dr. G. S. Hayes (formerlv Miss G. S. Layton) ably did most of the marshalling. Mr. M. H. B. Walker provided statistical help during the proiect. The drugs were provided by G. D. Searle \& Co. Ltd., and Dr. J. K. Butler of this firm also provided constant encouragement and interest. We owe, of course, a special debt of gratitude to our willing volunteers, none of whom ever defanlted.

Requests for reprints should be addressed to: Dr. T. A. Betts, University Department of Psychiatry, Queen Elizabeth Hospital, Birmingham B15 2TH. Details of the full analysis of the raw data can be obtained from either Dr. T. A. Betts or Dr. A. B. Clayton, Department of Transportation and Environmental Planning, The University, Birmingham B15 2TT.

\section{References}

Borkenstein, R. F., Crowther, R. F., Shumate, R. P., Ziel, W. B., and Zylman, R. (1964). Role of the Drinking Driver in Traffic Accidents,

Eysenck, H. I., and Eysenck, S. B. G. (1964). Manual of the Eysenck Personality Inventory, London, University of London Press.

Havard, J. D. J. (1970). British fournal of Hospital Medicine, 4, 455. Kelly, E. L., Miller, J. G., Marquis, D. G., Gerrard, R. W., and Uhr, L.

Kelly, E. L., Miller, J. G., Marquis, D. G., Gerrard, R. W., and Uhr, L. (1958b). Archives of Neurology and Psychiatry, 80, 247.

Kibrick, E., and Smart, R. G. (1970). Fournal of Safety Research, 2, 73. Kielholz, P., et al. (1967). Deutsche Medizinische Wochenschrift, 92, 1525. Kielholz, P., et al. (1969). Deutsche Medizinische Wochenschrift, 94, 301.

Lader, M. H., and Wing, L. (1966). Physiological Measures, Sedative Drug and Morbid Anxiety, Maudsley Monograph. No. 14. London, Oxford University Press.

Milner, G. (1972). Drugs and Driving, Basle, Karger.

Murray, N. (1960). Fournal of the American Medical Association, 173, 1760. Reisby, N., and Theilgaard, A. (1969). Acta Psychiatrica Scandanavica, Suppl.' No. 208.

Siegel, S. (1956). Nonparametric Statistics for the Behavioural Sciences, New York, McGraw Hill.

York, McGraw Hill.
Walker, H., and Lev, J. (1953). Statistical Inference. New York, Holt

Waller, J. A. (1971). Fournal of the American Medical Association, 215, 1477. 